\title{
Site-specific CpG methylation in the CCAAT/enhancer binding protein delta (CEBP $\delta)$ CpG island in breast cancer is associated with metastatic relapse
}

\section{Palmieri', , M Monteverde' ${ }^{2}$ L Lattanzio ${ }^{2}$, O Gojis ${ }^{1,3,4}$, B Rudraraju', M Fortunato ${ }^{5}$, N Syed ${ }^{6}$, A Thompson ${ }^{7}$, O Garrone ${ }^{8}$, M Merlano ${ }^{8}$, C Lo Nigro ${ }^{2,9}$ and T Crook ${ }^{7,9}$}

'Cancer Research UK Laboratories, Imperial Centre for Translational and Experimental Medicine, Division of Cancer, Imperial College London, Du Cane Road, London WI 2 ONN, UK; ${ }^{2}$ Laboratory of Cancer Research and Translational Oncology, Oncology Department, S. Croce General Hospital, Cuneo, Italy; ${ }^{3}$ Department of Gynaecology and Obstetrics, Third faculty of Medicine, Charles university in Prague, Ruska 87, Prague 10, 100 00, Czech Republic; ${ }^{4}$ Department of Pathology, Third faculty of Medicine, Charles university in Prague, Ruska 87, Prague 10, 100 00, Czech Republic; ${ }^{5}$ Pathology Department, S. Croce General Hospital, Cuneo, Italy; ${ }^{6}$ Department of Pathology, Imperial College Healthcare NHS Trust, Charing Cross Hospital, London W6 8RF, UK; ${ }^{7}$ Dundee Cancer Centre, Ninewells Hospital and Medical School, Dundee DDI 9SY, UK; ${ }^{8}$ Medical Oncology, Oncology Department, S. Croce General Hospital, Cuneo, Italy

BACKGROUND: The CCAAT/enhancer binding protein delta (CEBP $\delta$ ) is a member of a highly conserved family of basic region leucine zipper transcription factors. It has properties consistent with a tumour suppressor; however, other data suggest that CEBP $\delta$ may be involved in the metastatic process.

METHODS: We analysed the expression of CEBP $\delta$ and the methylation status of the CPG island in human breast cancer cell lines, in 107 archival cases of primary breast cancer and in two series of metastatic breast cancers using qPCR and pyrosequencing.

RESULTS: Expression of CEBP $\delta$ is downregulated in primary breast cancer by site-specific methylation in the CEBP $\delta$ CpG island. Expression is also downregulated in $50 \%$ of cases during progression from primary carcinoma to metastatic lesions. The CEBP $\delta$ CpG island is methylated in $81 \%$ metastatic breast cancer lesions, while methylation in the CEBP $\delta$ CpG island in primary cancers is associated with increased risk of relapse and metastasis.

CONCLUSION: CCAAT/enhancer binding protein delta CPG island methylation is associated with metastasis in breast cancer. Detection of methylated CEBP $\delta$ genomic DNA may have utility as an epigenetic biomarker of primary breast carcinomas at increased risk of relapse and metastasis.

British Journal of Cancer (2012) I 107, 732-738. doi:I0.1038/bjc.20I2.308 www.bjcancer.com

Published online 10 July 2012

(C) 2012 Cancer Research UK

Keywords: breast cancer; CEBPD; methylation; metastasis

The CCAAT/enhancer binding proteins (CEBPs) are a highly conserved family of basic region leucine zipper (bZip) transcription factors, and comprises six family members (CEBP $\alpha$ to CEBP $\zeta$ ) (Ramji and Foka, 2002). The CEBP proteins exhibit significant amino acid homology $(>90 \%)$ in the bZip (C-terminal) domain, while the N-terminal regions are quite divergent exhibiting $<20 \%$ sequence homology (Ramji and Foka, 2002). The CEBP form homo- or heterodimers with each other as well as other bZipcontaining proteins such as Jun and Fos (Vinson et al, 2002), with the dyad symmetrical repeat RTTGCGYAAY (where R is A or G, and $\mathrm{Y}$ is $\mathrm{C}$ or $\mathrm{T}$ ) considered to be the optimal CEBP binding site (Osada et al, 1997). The CEBP $\delta$ unlike other family members lacks an activation domain and, therefore, represses gene transcription by forming inactive heterodimers with other members (Cooper et al, 1995). The CEBP family is involved in a number of key cellular processes including differentiation, metabolism, inflammation, apoptosis and proliferation (Wang et al, 1995; Yamanaka et al, 1997; Zinszner et al, 1998; Robinson et al, 1998).

*Correspondence: Dr C Palmieri; E-mail: c.palmieri@imperial.ac.uk

${ }^{9}$ These authors contributed equally to this work.

Received 26 April 2012; revised 6 June 2012; accepted 13 June 2012; published online 10 July 2012
CCAAT/enhancer binding protein delta has been proposed to have tumour suppressor function given its ability to decrease levels of cyclin D1 and cyclin E, while increasing p27 (Gery et al, 2005; Ikezoe et al, 2005; Pawar et al, 2010), as well as regulating proapoptotic gene expression during mammary gland involution (Thangaraju et al, 2005; Stein et al, 2009). Treatments in vitro, which induce growth arrest such as serum and growth factor withdrawal, increase $C E B P \delta$ expression and induce growth arrest in breast cancer cell lines as well as in human mammary epithelial cells (O'Rourke et al, 1997; Sivko and DeWille, 2004). However, in vivo loss of $\operatorname{CEBP} \delta$ results in increased mammary epithelial cell proliferation and ductal hyperplasia, supporting the importance of $\mathrm{CEBP} \delta$ in regulating mammary epithelial growth in vivo (Gigliotti et al, 2003). These data are supported by the reduction observed in CEBP $\delta$ expression in mammary tumour-prone MMTV-c-neu transgenic mice and in carcinogen-induced rodent mammary tumours (Porter et al, 2001; Kuramoto et al, 2002). Further evidence that $\operatorname{CEBP} \delta$ is a tumour suppressor comes from animal data using mice with a germ-line deletion of $C E B P \delta$ (on a MMTV-c-neu background), with these animals developing significantly more breast tumours compared with controls (Balamurugan et al, 2010). Interestingly, in the context of this mouse knockout model absence of $C E B P \delta$ resulted in less efficient metastasis under hypoxia, implying that the 
protein may be required for metastasis at least under these conditions (Balamurugan et al, 2010).

CCAAT/enhancer binding protein delta is downregulated via methylation in cervical cancer, hepatocellular carcinoma and AML (Agrawal et al, 2007; Ko et al, 2008). CCAAT/enhancer binding protein delta protein expression also correlates with low-grade histology and disease-free survival in meningiomas (Barresi et al, 2009). CCAAT/enhancer binding protein delta has also been shown to be downregulated in ductal carcinoma in situ as compared to normal breast tissue (Porter et al, 2003). In a series of primary human breast cancers, $C E B P \delta$ mRNA levels were very low in $32 \%$ (18 out of 57) of cases, and in those cases with low mRNA levels, and this was associated with $\mathrm{CpG}$ methylation in the $C E B P \delta$ gene promoter and $5^{\prime}$ coding region (Tang et al, 2006). CEBP $\delta$ also formed part of 70-gene signature, which predicted better survival of breast cancer patients (Naderi et al, 2007).

To date, there have been no reports regarding the involvement of $C E B P \delta$ in metastasis in human cancer, nor of the utility of $C E B P \delta$ as a prognostic biomarker in breast cancer. Here we have performed quantitative analysis of $C E B P \delta \mathrm{CpG}$ island methylation to test these possibilities.

\section{MATERIALS AND METHODS}

\section{Breast cancer cell lines}

Breast carcinoma cell lines SKBR3, MDA-MB231, MDA-MB 453, MDA-MB468, MDA-MB 435, MCF7, T47D, ZR75.1, HCC1937, HS578 were grown as described previously (Shah et al, 2009).

Two series of cases were analysed in the study. The first was 107 primary breast carcinomas. The characteristics of this patient population are shown in Table 1. These cases were randomly selected from the tissue archives of S. Croce General Hospital,

Table I Clinico-pathological features of primary breast cancers

\begin{tabular}{|c|c|}
\hline$N=107$ & $\mathbf{N}(\%)$ \\
\hline \multicolumn{2}{|l|}{ Age } \\
\hline Median age (years) & 63.0 (Range: 36-87) \\
\hline \multicolumn{2}{|l|}{ Tumour size } \\
\hline $0-20 \mathrm{~mm}$ & 42 (39) \\
\hline$>20$ to $50 \mathrm{~mm}$ & $40(37)$ \\
\hline$>50 \mathrm{~mm}$ & $3(3)$ \\
\hline Not known & $22(21)$ \\
\hline \multicolumn{2}{|l|}{ Tumour grade } \\
\hline Grade I & $7(7)$ \\
\hline Grade II & $82(77)$ \\
\hline Grade III & $12(11)$ \\
\hline Not known & $6(6)$ \\
\hline \multicolumn{2}{|l|}{ Nodal status } \\
\hline Positive & $4 \mid(38)$ \\
\hline Negative & $51(48)$ \\
\hline Not known & $15(14)$ \\
\hline \multicolumn{2}{|l|}{ Hormone receptor status } \\
\hline $\mathrm{ER}+$ ve and $\mathrm{PgR}+$ ve unknown & $70(65)$ \\
\hline $\mathrm{ER}+$ ve and $\mathrm{PgR}-\mathrm{ve}$ & $35(33)$ \\
\hline $\mathrm{ER}+$ ve and PgR unknown & $2(2)$ \\
\hline \multicolumn{2}{|l|}{ HER2 status } \\
\hline Positive $(3+/ 2+$ FISH positive $)$ & $14(13)$ \\
\hline Negative & $86(80)$ \\
\hline Not known & $7(7)$ \\
\hline
\end{tabular}

Abbreviations: $\mathrm{ER}=$ oestrogen receptor; $\mathrm{FISH}=$ fluorescence in situ hybridisation; $\mathrm{PgR}=$ progesterone receptor.
Cuneo, Italy. For all 107 cases, genomic DNA was available and was analysed by pyrosequencing for $C E B P \delta$ CpG island methylation. For 26 of the 107 cases, mRNA was available and was used to analyse $C E B P \delta$ expression by qPCR. At the time of the study, metastatic relapse had occurred in 31 of the 107 patients. For 14 of 31 relapsed cases, tissue from the metastasis was available and was analysed in parallel with matched tissue from the primary cancer for $C E B P \delta$ expression. The second series comprised 21 central nervous system (CNS) metastatic lesions from Imperial Healthcare NHS Trust. These cases were identified from the neuropathology archives at Charing Cross Hospital, London. Tissue was originally obtained at neurosurgical resection of intracranial disease in patients with a pre-existing diagnosis of breast cancer and was confirmed by histopathology to be metastatic breast cancer. Genomic DNA from this series was analysed by pyrosequencing for $C E B P \delta \mathrm{CpG}$ island methylation. The study received ethical committee approval in both centres. In all cases, the original diagnosis and adequate representation of neoplastic tissue was confirmed by histopathological review prior to inclusion in the study. Expression of the oestrogen receptor (ER), the progesterone receptor and HER2 was determined according to local protocols.

\section{Analysis of $C E B P \delta$ expression}

Total RNA was extracted from formalin-fixed paraffin-embedded (FFPE) tissue using Recover All kit (Ambion, Carlsbad, CA, USA). cDNA was synthesised from $1 \mu \mathrm{g}$ total RNA using the High Capacity cDNA Reverse Transcription kit (Applied Biosystems, Foster City, CA, USA). For demethylation, cells were treated with $5 \mu \mathrm{m}$ 5'azacytidine (Sigma, Gillingham, UK) for 7 days. Cells were split every 2-3 days with the addition of fresh drug. After drug treatment, cells were harvested for qPCR. For qPCR analysis, 25- $\mu \mathrm{l}$ PCRs were performed using $50 \mathrm{ng}$ of cDNA obtained by reverse transcription. Amplification and analysis were done according to the manufacturer's protocol in 96-well plates in an ABI PRISM 7000 Sequence Detection System (Applied Biosystems) and using the pre-cast 'TaqMan Gene Expression Assays' (Applera, https:// products.appliedbiosystems.com/) for CEBPS (Hs00270931_s1). Quantification of target transcripts was performed in comparison to the reference transcript $\beta_{2}$-microglobulin (Hs99999907_m1) using the ' $\Delta \Delta C_{\mathrm{t}}$ method for comparing relative expression results in real-time PCR' as outlined by PE Applied Biosystems (Perkin Elmer, Forster City, CA, USA).

\section{Pyrosequencing}

Genomic DNA was extracted from cellular pellets and FFPE sections using the DNeasy Mini kit (Qiagen, Crawley, UK) according to the manufacturer's instructions, and from 10 micron sections of FFPE using phenol with the traditional protocol. Methylation in the $\mathrm{CpG}$ island of $C E B P \delta$ was analysed by pyrosequencing technology, which allows the quantification of the degree of methylation at each CG site through the calculation of the ratio between $\mathrm{T}$ and $\mathrm{C}$. PCR primers were as follows:

Forward: BIOT-5'-GGAGTGTTGGTAGAGGGAG-3'

Reverse: 5'-CCCTAAAAACCCCCAACCC-3'.

The PCR conditions were as follows: $95^{\circ} \mathrm{C}$ for $10 \mathrm{~min}, 95^{\circ} \mathrm{C}$ for $30 \mathrm{~s}$, $58^{\circ} \mathrm{C}$ for $30 \mathrm{~s}, 72^{\circ} \mathrm{C}$ for $40 \mathrm{~s}$ for 40 cycles, $72^{\circ} \mathrm{C}$ for $7 \mathrm{~min}$. The PCR products were then analysed by pyrosequencing using the Sample Prep kit (Diatech, Jesi, Italy).

After pyrosequencing, analysis of percentage methylation at each CG was determined using Pyromark Q CpG Software (Qiagen, Venlo, The Netherland). DNA from five normal breast samples and placental DNA were used as a negative control for methylation ( $0 \%$ average methylation), and a commercial methylated DNA (Millipore, Billerica, MA, USA) was used as positive control (98\% average methylation). 


\section{Statistical analysis}

The CEBP $\delta \mathrm{CpG}$ island methylation status and presence of metastatic profile were assessed for associations using the $\chi^{2}$-test, with Yates correction or Fisher exact test when appropriate. All the comparisons are two-tailed.

\section{RESULTS}

Site-specific CpG methylation correlates with silencing of $C E B P \delta$ in breast cancer cell lines

We analysed expression and epigenetic regulation of $C E B P \delta$ in a panel of breast carcinoma cell lines. Because a previous report has identified methylation-associated downregulation of $C E B P \delta$ in the SUM-52PE breast carcinoma cell line (Tang et al, 2006), we were interested to further test and characterise the relationship between expression of $C E B P \delta$ mRNA and methylation in breast carcinoma cell lines. We wished to use a fully quantitative analytical technique rather than methylation-specific PCR (MSP) and we therefore used pyrosequencing to analyse a section of the $C E B P \delta$ CpG island (Figure 1). In breast cancer cell lines, methylation was predominantly but not exclusively seen at CG 5 in the fragment analysed by pyrosequencing (Figure 1). CCAAT/enhancer binding protein delta mRNA was detectable in many cell lines. Expression was highest in HCC1937 and ZR75.1, but was downregulated relative to normal breast cells in several cell lines (Figure 1). There was a good correlation between methylation at CG 5 of the analysed fragment and downregulation of the mRNA expression (Figure 1).

\section{$C E B P \delta$ is downregulated in primary breast carcinomas compared with normal breast tissue}

Next we sought to investigate whether there is downregulation of $C E B P \delta$ mRNA in clinical cases of breast cancer, and we performed qPCR in 26 primary breast carcinomas. CCAAT/enhancer binding protein delta mRNA was reduced relative to normal breast tissue in many cases (Figure 2A). Expression was reduced most strikingly in the series of primary cancers, which later relapsed in comparison to cases which did not relapse: downregulation by at least $50 \%$ compared with normal breast epithelium was observed in 1 out of 7 non-relapsing cases and 11 out of 19 relapsing cases (compare upper and lower panels in Figure 2A).

\section{Downregulation of $C E B P \delta$ in metastatic breast cancer lesions}

We then analysed expression of $C E B P \delta$ in metastatic breast cancer lesions. We examined a series of 14 cases comprising the primary breast carcinoma together with the paired metastasis, which had been confirmed by histopathology. Clinico-pathological details and sites of metastasis for each pair are shown in Table 2. Using qPCR, we analysed expression of $C E B P \delta$. In 7 out of $14(50 \%)$ cases, we observed a significant reduction in $C E B P \delta$ mRNA in the metastasis relative to the primary cancer, consistent with selective pressure for loss of $C E B P \delta$ expression with acquisition of a metastatic phenotype in breast cancer (Figure 2B).

\section{$C E B P \delta$ CpG island methylation predicts breast cancer relapse}

We next analysed a series of 107 cases of primary breast cancer from the same patient population to determine whether analysis of $\mathrm{CpG}$ island methylation in $C E B P \delta$ has utility as a biomarker predictive of clinical relapse. Clinico-pathological details of the study population are shown in Table 1 . Representative analyses showing the distribution of methylation in the amplified area of the $\mathrm{CpG}$ island are shown in Figure 3. Consistent with breast
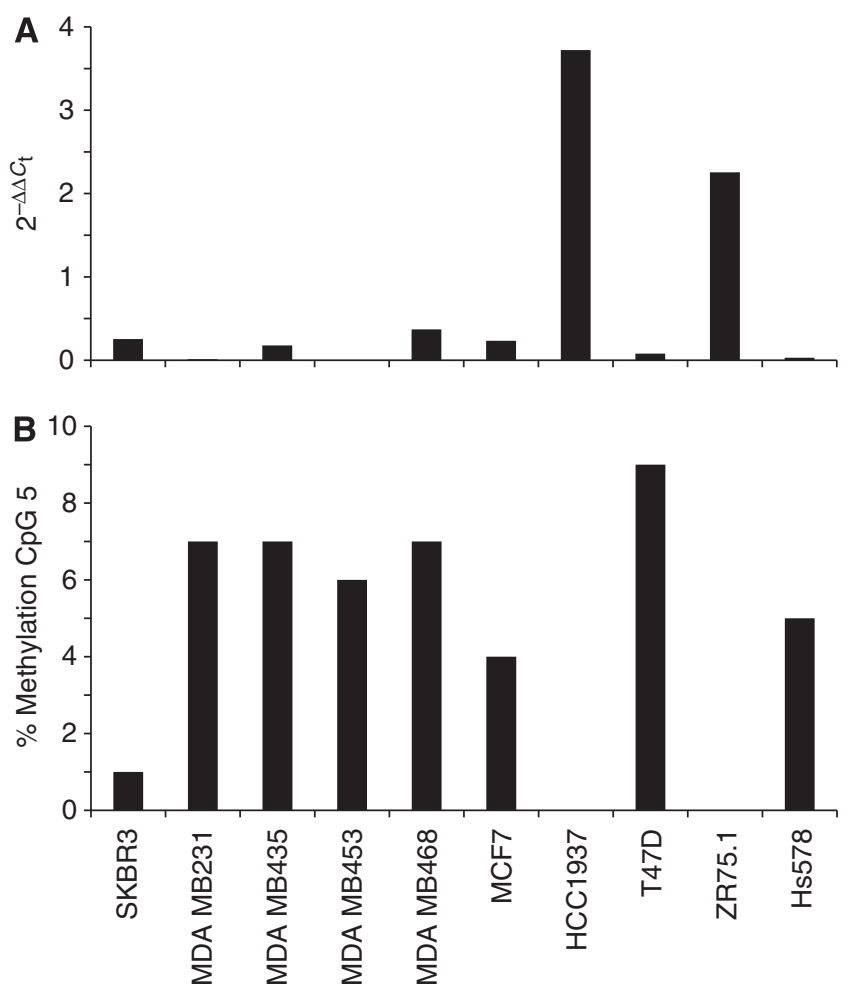

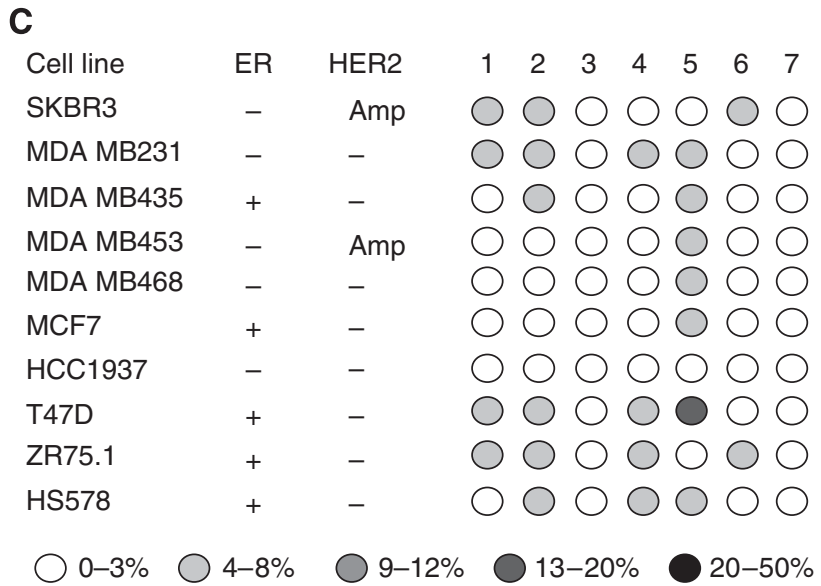

Figure I Downregulation of CEBP $\delta$ mRNA in breast carcinoma cell lines correlates with site-specific CpG methylation in the CEBP $\delta$ CpG island. (A) Expression of CEBP $\delta$ in breast carcinoma cell lines. qPCR was performed as described in Materials and methods. (B) Site-specific $\mathrm{CpG}$ island methylation in breast carcinoma cell lines. The percentage methylation at CG 5, as determined by pyrosequencing, is indicated. (C) Map of CpG methylation in the CEBPS CpG island in breast cancer cell lines. Pyrosequencing was performed as described in Materials and methods. The level of methylation is represented by the intensity of shading in the circles, each of which represents an individual CG dinucleotide in the amplified fragment.

carcinoma cell lines, methylation at individual CG dinucleotides was variable. In the clinical cases, methylation was most dense in CG 4-7 in the analysed fragment (Figure 3A), CGs 2 and 3 being almost entirely unmethylated in all cases. Methylation correlated well with reduced expression of $C E B P \delta$ mRNA (Figure 3B). The distribution of $C E B P \delta$ CpG island methylation between cases relapsing with metastatic disease and non-relapsing cases is shown in Figure 4. At the time of censor, $29 \%$ (31 of 107) of cases had relapsed. By using a mean percentage $\mathrm{CpG}$ methylation cutoff 
A
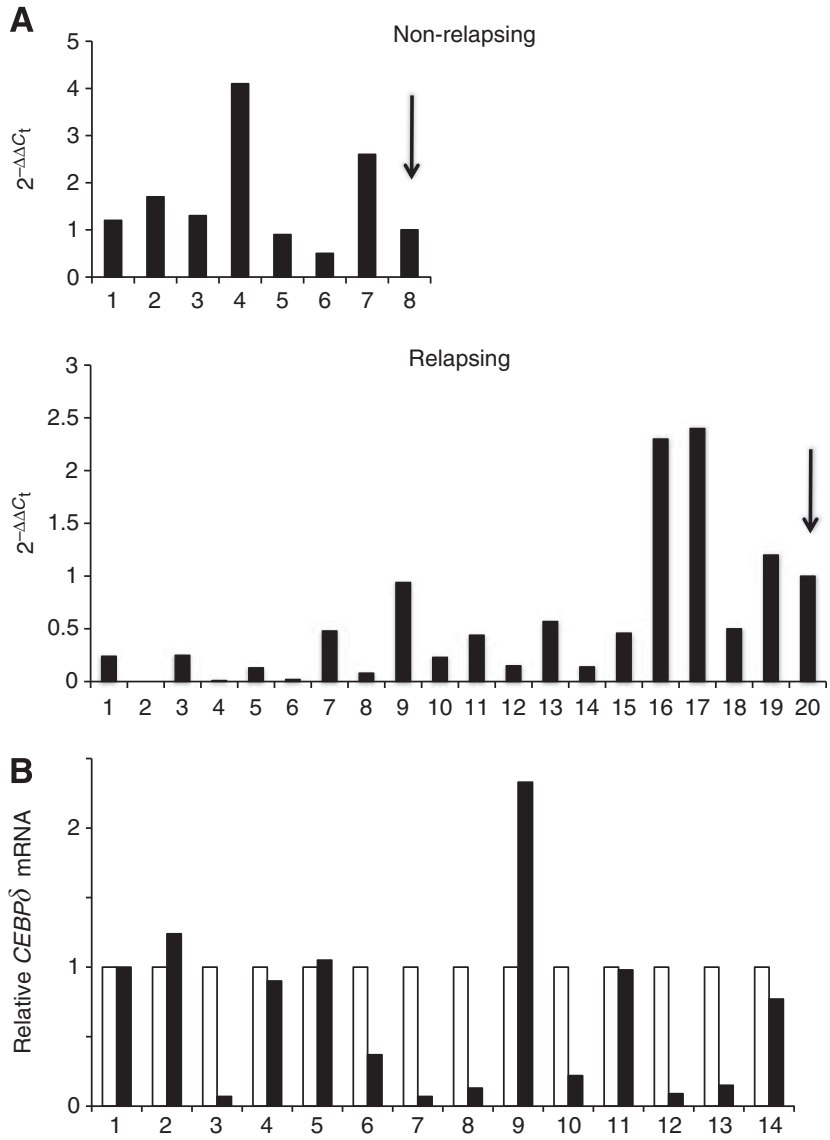

Figure 2 Expression of CEBP $\delta$ is downregulated in clinical cases of breast cancer. (A) Expression of CEBP $\delta$ in primary breast carcinomas. The figure shows mRNA levels determined by qPCR as described in Materials and Methods. $2^{-\Delta \Delta C_{\mathrm{t}}}$ was calculated as described in Materials and Methods relative to CEBP $\delta$ expression in control normal breast tissue (arrowed). The upper panel shows expression in cases which had not relapsed at the time of censor, the lower panel shows cases which had relapsed at the time of censor. (B) Expression of CEBP $\delta$ is frequently downregulated in metastatic breast cancer. The figure shows 14 paired primary/metastasis cases. In each case, expression in the primary breast cancer (open box) is set at $\mid$ and expression in the metastasis (black box) is relative to this. Expression is downregulated in cases $3,6,7,8,10,12$ and 13 .

Table 2 Receptor status of primary invasive breast cancer, site of initial relapse and site biopsied

\begin{tabular}{|c|c|c|c|}
\hline Case & Primary tumour & Relapse sites & Relapse biopsied site \\
\hline । & $\mathrm{ER}+\mathrm{PgR}+\mathrm{HER} 2-$ & ST, Sk & Sk \\
\hline 2 & $\mathrm{ER}+\mathrm{PgR}+\mathrm{HER} 2-$ & LN, Sk & LN \\
\hline 3 & $\mathrm{ER}+\mathrm{PgR}-\mathrm{HER} 2+$ & $\mathrm{Br}, \mathrm{Li}, \mathrm{LN}, \mathrm{Lu}$ & LN \\
\hline 4 & $\mathrm{ER}+\mathrm{PgR}+\mathrm{HER} 2-$ & Bo, Lu & $\mathrm{Lu}$ \\
\hline 5 & ER - PgR - HER2 + & Li, LN, Sk & LN \\
\hline 6 & $\mathrm{ER}-\mathrm{PgR}-\mathrm{HER} 2+$ & LN & LN \\
\hline 7 & ER - . PgR - HER2 - & ST, Sk & Sk \\
\hline 8 & $\mathrm{ER}+\mathrm{PgR}-\mathrm{HER} 2-$ & LN, ST & LN \\
\hline 9 & $\mathrm{ER}+\mathrm{PgR}+\mathrm{HER} 2-$ & Sk & Sk \\
\hline 10 & $\mathrm{ER}+\mathrm{PgR}+\mathrm{HER} 2-$ & Cw, Sk & Sk \\
\hline 11 & $\mathrm{ER}+\mathrm{PgR}-\mathrm{HER} 2+$ & Cw, Sk & Sk \\
\hline 12 & $\mathrm{ER}+\mathrm{PgR}+\mathrm{HER} 2-$ & Bo, Li, Sk & Sk \\
\hline 13 & $\mathrm{ER}+\mathrm{PgR}+\mathrm{HER} 2-$ & Bo, Li, LN & LN \\
\hline 14 & $\mathrm{ER}+\mathrm{PgR}+\mathrm{HER} 2-$ & Bo & Bo \\
\hline
\end{tabular}

Abbreviations: $\mathrm{Bo}=$ bone; $\mathrm{CW}=$ chest wall; $\mathrm{ER}=$ oestrogen receptor; $\mathrm{Li}=$ liver $\mathrm{LN}=$ lymph node; $\mathrm{Lu}=$ lung; $\mathrm{PgR}=$ progesterone receptor; $\mathrm{Sk}=$ skin; $\mathrm{ST}=$ soft tissue.
A ER HER2 Recurrence $\begin{array}{lllllll}1 & 2 & 3 & 4 & 5 & 6 & 7\end{array}$

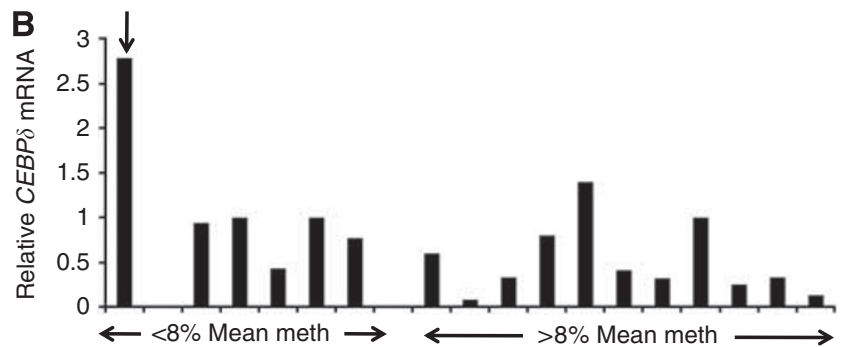

Figure 3 Methylation-associated transcriptional silencing of CEBP $\delta$ in primary breast carcinomas. (A) Representative pyrosequencing analyses of the CEBP $\delta$ CpG island in primary breast carcinomas. The upper 12 cases were non-relapsing, the lower 12 cases later relapsed at distant metastatic sites. The level of methylation is represented by the intensity of shading in the circles, each of which represents an individual CG dinucleotide in the amplified fragment as indicated in the figure. (B) Association of CEBP $\delta$ CPG island methylation with downregulation of CEBP $\delta$ mRNA levels. Expression of CEBP $\delta$ was determined by $\mathrm{qPCR}$ and $\mathrm{CpG}$ methylation by pyrosequencing as described in Materials and Methods. Cases are divided into those with mean \% CG methylation below $(<)$ or above $(>)$ 8. Also shown is expression in normal breast epithelium (arrowed).

of $8 \%$, as determined by pyrosequencing, relapse was significantly more frequent in cases in which the $C E B P \delta$ CpG island was positive for methylation $(P=0.0006$ by Fisher's Exact test; $P=0.001$ with Yates correction).

\section{$\operatorname{CEBP} \delta$ CpG island methylation is associated with metastatic breast cancer}

We had previously shown that expression of $C E B P \delta$ is downregulated in metastatic breast cancer lesions (Figure 2B). We wished to test whether $C E B P \delta \mathrm{CpG}$ island methylation is associated with increased risk of distant organ metastasis in breast cancer and we asked whether there was an association between $C E B P \delta$ CpG island methylation and metastasis at specific organ sites. Metastases in liver $(P=0.01)$, lymph node $(P=0.02)$ and skin $(P=0.02)$ were more common in cases in which the primary cancer was positive for methylation (using a mean percentage $\mathrm{CpG}$ methylation cutoff of $8 \%$ as determined by pyrosequencing). In contrast, metastases in bone and lung were not significantly 


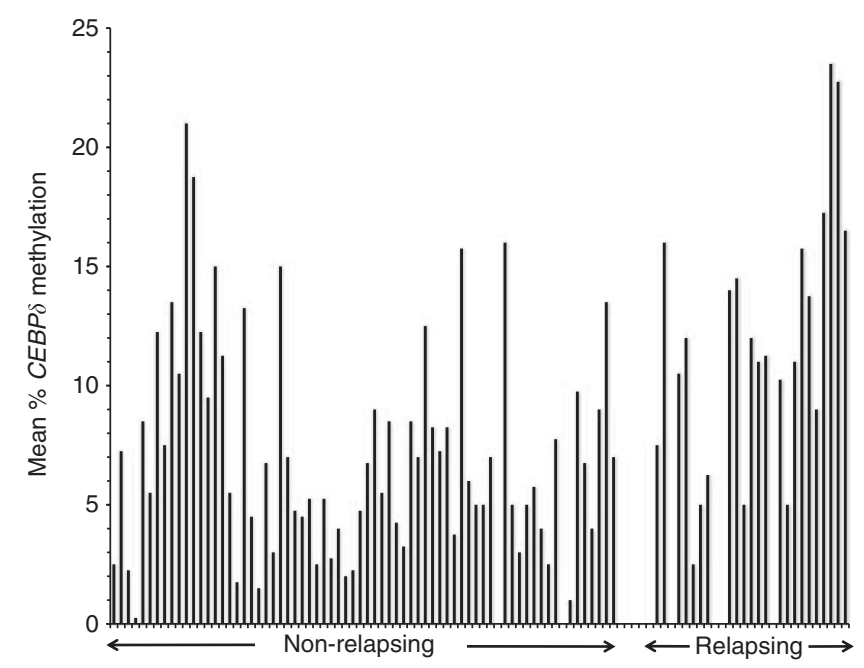

Figure $4 C E B P \delta C P G$ island methylation is increased in primary breast carcinomas which subsequently relapse. The figure shows distribution of CEBP $\delta$ CPG island methylation in cases which at the time of censor had either relapsed or not relapsed. Mean percentage CpG methylation, determined by pyrosequencing, is shown in relapsing and non-relapsing cases.

affected by the methylation status of the CEBP $\delta$ CpG island ( $P=0.13$ and $P=0.24$, respectively). The frequency of brain metastases was higher in cases in which the primary cancer was positive for $C E B P \delta \mathrm{CpG}$ island methylation, but this just failed to reach significance $(P=0.06)$ due to the small number of cases with brain metastases. To extend these observations, we analysed $C E B P \delta$ CpG island methylation by pyrosequencing in a series of 21 CNS metastases, confirmed by histopathology to be derived from primary breast carcinomas (Figure 5). As observed previously, methylation was most dense at CG 4 and CG 5 and was detected in $81 \%$ (17 out of 21 ) of cases (Figure 5). For three of the cases, the paired breast cancer primary was also available to us. In one of the three cases, there was a change in methylation in the CNS metastasis in comparison with the primary, with acquisition of methylation at CGs 4, 5 and 6 in the metastasis (Figure 5).

\section{DISCUSSION}

We have investigated the expression and regulation of CEBP $\delta$ in breast cancer. We show that the gene is a frequent target for downregulation in primary breast carcinomas, as a result of methylation in the $\mathrm{CpG}$ island. Furthermore, we demonstrate that methylation in $C E B P \delta$ is associated with metastasis and that methylation, when analysed with high-resolution, quantitative methodology may have utility as a biomarker predictive of future metastatic relapse. We were initially interested to investigate this gene because there is experimental evidence that CEBP $\delta$ has tumour suppressor properties (Porter et al, 2001; Kuramoto et al, 2002 ) and yet, at least in some animal models, may be involved in metastasis (Balamurugan et al, 2010). The data we present are consistent with and supportive of a tumour suppressor and metastasis suppressor function in human breast cancer.

We initially studied expression in a panel of established breast carcinoma cell lines and demonstrated that expression was reduced in several of the cell lines. Some studies of candidate epigenetically regulated biomarker genes use non-quantitative, low-resolution techniques such as methylation-dependent PCR (MSP) to analyse methylation. Here we have used pyrosequencing that allows high-resolution quantification of percentage methylation at individual CG dinucleotides within a defined section of the $\mathrm{CpG}$ island. We observed using pyrosequenicng that methylation
$\mathrm{CpG}$

$$
\begin{array}{lllllll}
1 & 2 & 3 & 4 & 5 & 6 & 7
\end{array}
$$

\begin{tabular}{|c|}
\hline Primary 1 \\
\hline Brain met 1 \\
\hline Primary 2 \\
\hline Brain met 2 \\
\hline Primary 3 \\
\hline Brain met 3 \\
\hline
\end{tabular}

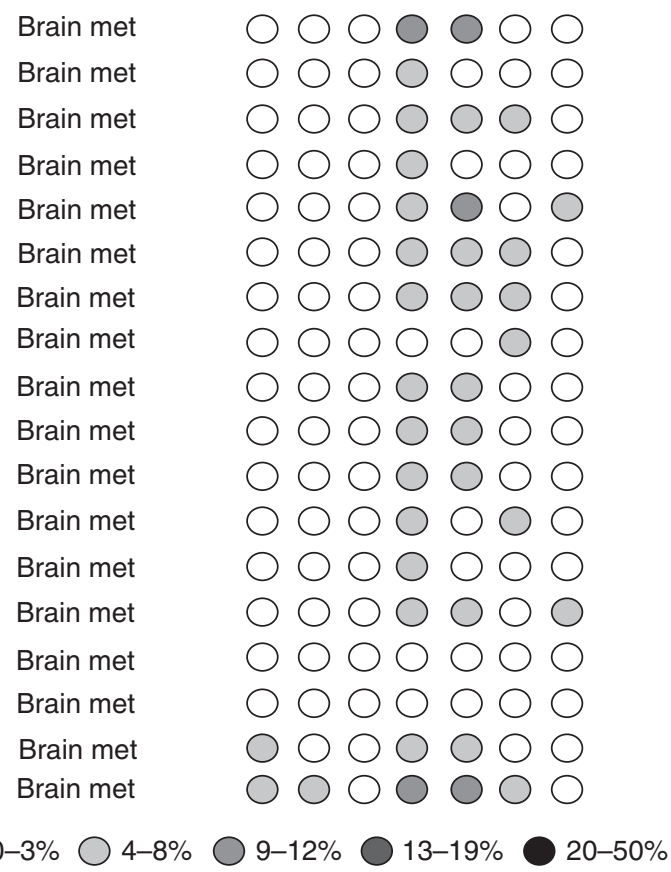

Figure $5 C E B P \delta C p G$ island methylation in breast cancer central nervous system (CNS) metastases. The figure shows pyrosequencing analysis of the CEBP $\delta$ CpG island in CNS metastatic lesions, confirmed by histopathology to be metastatic breast cancer. Also shown (top) are three paired primaryl CNS metastatic breast cancers. Pyrosequencing was done as described in Materials and methods. The level of methylation is represented by the intensity of shading in the circles, each of which represents an individual CG dinucleotide in the amplified fragment.

at CG5 in the analysed region of the CpG island showed a good correlation with transcriptional silencing in a panel of breast cancer cell lines. Our data showing correlation between methylation and downregulation of expression in both breast cancer cell lines and primary carcinomas are supported by other studies in hepatocellular carcinoma (Ko et al, 2008).

We then extended these initial studies to investigate the possible role of downregulation of $C E B P \delta$ in breast cancer metastasis. Several lines of evidence from our studies support loss of $C E B P \delta$ expression as a determinant of metastasis. First, analysis of paired primary/metastatic lesions showed clear downregulation in the metastases in $50 \%$ of cases. Very few studies have specifically examined changes in expression of individual genes during metastasis in breast cancer. Our data are clearly consistent with selective pressure for loss of $\operatorname{CEBP} \delta$ during acquisition of a metastatic phenotype. Second, we have shown that the presence of methylation in the $C E B P \delta \mathrm{CpG}$ island in primary breast carcinomas is associated with an increased risk of relapse and of distant organ metastasis. Third, we show that the CEBP $\delta \mathrm{CpG}$ island is frequently methylated in CNS metastases shown to originate in primary breast carcinomas. Further we have also shown herein, albeit in limited numbers of cases, that methylation in $C E B P \delta$ may be acquired during metastasis to the CNS, consistent 
with epigenetic evolution as cells acquire metastatic properties. Methylation of the CEBP $\delta$ CpG island as an important event in breast cancer metastasis is consistent with a previous report, implicating downregulation of CEBP $\delta$ (among other genes) in breast carcinoma cell lines with increased propensity for CNS metastasis (Bos et al, 2009).

Our current data in early breast cancer are consistent with $\operatorname{CEBP} \delta$ being a tumour suppressor (Gery et al, 2005; Ikezoe et al, 2005; Balamurugan et al, 2010; Pawar et al, 2010). However, our data reporting fewer metastasis when $C E B P \delta$ is not methylated are at face value at odds with the in vivo data, where loss of $\operatorname{CEBP} \delta$ is associated with fewer metastasis (Balamurugan et al, 2010). Possible explanations for the difference include the fact that the study of Balamurugan et al (2010) is from an animal experimental system, whereas the present data are derived from human breast cancer samples. Furthermore, the model used was in a HER2 overexpressing background (Guy et al, 1992), while in the current series only $13 \%$ of cases were HER 2 positive. In addition, only data relating to lung metastasis were reported, with no data with regard to the effect of CEBP $\delta$ on involvement of other common sites for metastasis or overall metastatic tumour burden. It is known within the context of human breast cancer that HER2-positive breast cancer not only has a predilection to metastasis to the lung but also to the brain and liver (Kennecke et al, 2010). Therefore, the phenotype seen may be specific to the animal model in question. Furthermore, the underlying mechanism proposed for the effect observed in vivo was related to hypoxic HIF-1 $\alpha$ accumulation and hypoxia adaptation. As such, these conditions may therefore be prerequisite for the effect observed and may in be part dependent on HER2 (Balamurugan et al, 2010).

It should be noted, of course, that $C E B P \delta$ is not the only gene contributing to a metastatic profile. The current data show that methylation of $C E B P \delta$ in the primary tumour (using a mean percentage CpG methylation cutoff of $8 \%$ as determined by pyrosequencing) is associated with metastasis in the liver, lymph node and skin, with metastases in bone and lung not being significantly influenced by the methylation status of $C E B P \delta$. Multiple additional genes must be at play and we have previously shown the importance of one such candidate CACNA2D3 in the metastatic process (Palmieri et al, 2012).

The patient population analysed in our study consisted predominantly of ER-positive cases treated with adjuvant endocrine therapy.
A key question in the management of early breast cancer continues to be risk stratification to identify patients likely to relapse despite being deemed to be at low risk by clinico-pathological parameters such as those in the St Gallen criteria. Such patients could then be offered appropriate systemic therapy such as adjuvant chemotherapy. While others could be spared such treatment if their risk could objectively be determined to be low. We have shown herein that methylation in the $C E B P \delta \mathrm{CpG}$ island correlates with a significantly increased risk of metastatic relapse at distant organ sites including brain and liver. Our data imply that $C E B P \delta$ may have utility as a biomarker predictive of relapse and metastasis and thus in the identification of patients who may derive greater benefit from adjuvant treatment.

In conclusion, we show that transcriptional silencing of $C E B P \delta$ is associated with metastasis in breast cancer. Validation of these results in larger, independent cohorts of patients is required and if positive would encourage the inclusion of $C E B P \delta$ in molecular risk assessment algorithms to inform the use of adjuvant therapy in breast cancer.

\section{ACKNOWLEDGEMENTS}

Carlo Palmieri is the recipient of a Cancer Research UK Clinician Scientist award and also acknowledges support from Imperial College Healthcare Charity. Ondrej Gojis is in part funded by a grant from the Ministry of Education of the Czech Republic (Project 'Oncology' MSM 0021620808) and is also a recipient of the Translational Research Fellowship from the European Society of Medical Oncology and a fellowship from the European Society for Surgical Oncology. The Division of Cancer at Imperial College London, Imperial College Healthcare NHS Trust is an Experimental Cancer Medicine Centre that is supported by funds from Cancer Research UK and the Department of Health (C37/A7283), and also forms part of the Imperial Cancer Research UK Centre (C42671/A12196). We would like to thank Prof Gerry Thomas, Sarah Chilcott-Burns and the Imperial College Healthcare NHS Trust, Human Biomaterials Resource Centre (Tissue Bank). Nelofer Syed acknowledges support from the Brain Tumour Research Campaign. Tim Crook is a Scottish Senior Clinical Fellow in Medical Oncology. We thank De Federico Roncaroli for his contribution to the work.

\section{REFERENCES}

Agrawal S, Hofmann WK, Tidow N, Ehrich M, van den Boom D, Koschmieder S, Berdel WE, Serve H, Müller-Tidow C (2007) The C/ EBPdelta tumor suppressor is silenced by hypermethylation in acute myeloid leukemia. Blood 109: 3895-3905

Balamurugan K, Wang JM, Tsai HH, Sharan S, Anver M, Leighty R, Sterneck E (2010) The tumour suppressor C/EBP $\delta$ inhibits FBXW7 expression and promotes mammary tumour metastasis. EMBO J 29: 4106-4117

Barresi V, Vitarelli E, Cerasoli S, Barresi G (2009) The cell growth inhibitory transcription factor C/EBPdelta is expressed in human meningiomas in association with low histological grade and proliferation index. J Neurooncol 97: 233-240

Bos PD, Zhang XH, Nadal C, Shu W, Gomis RR, Nguyen DX, Minn AJ, van der Vijver MJ, Gerald WL, Foekens JA, Massague J (2009) Genes that mediate breast cancer metastasis to the brain. Nature 459: 1005-1009

Cooper C, Henderson A, Artandi S, Avitahl N, Calame K (1995) Ig/EBP(C/ $\mathrm{EBP} \delta)$ is a transdominant negative inhibitor of C/EBP family of transcriptionalactivators. Nucleic Acids Res 23: 4371-4377

Gery S, Tanosaki S, Hofmann WK, Koppel A, Koeffler HP (2005) C/EBPdelta expression in a BCR-ABL-positive cell line induces growth arrest and myeloid differentiation. Oncogene 24: 1589-1597

Gigliotti AP, Johnson PF, Sterneck E, DeWille JW (2003) Nulliparous CCAAT/ enhancer binding proteindelta (C/EBPdelta) knockout mice exhibit mammary gland ductal hyperlasia. Exp Biol Med 228: 278-285

Guy CT, Webster MA, Schaller M, Parsons TJ, Cardiff RD, Muller WJ (1992) Expression of the neu protooncogene in the mammary epithelium of transgenic mice induces metastatic disease. Proc Natl Acad Sci USA 89: $10578-10582$

Ikezoe T, Gery S, Yin D, O'Kelly J, Binderup L, Lemp N, Taguchi H, Koeffler HP (2005) CCAAT/enhancer-binding protein delta: a molecular target of 1,25-dihydroxyvitaminD3 in androgen-responsive prostate cancer LNCaP cells. Cancer Res 200565 4762-4768

Kennecke H, Yerushalmi R, Woods R, Cheang MC, Voduc D, Speers CH, Nielsen TO, Gelmon K (2010) Metastatic behavior of breast cancer subtypes. J Clin Oncol 28: 3271-3277

Ko C-Y, Hsu H-C, Shen M-R, Chang W-C, Wang J-M (2008) Epigenetic silencing of CCAAT Enhancer-binding Protein d activity by YY1/ Polycomb Group/DNA methyltransferase complex. J Biol Chem 283: 30919-30932

Kuramoto T, Morimura K, Yamashita S, Okochi E, Watanabe N, Ohta T, Ohki M, Fukushima S, Sugimura T, Ushijima T (2002) Etiology-specific gene expression profiles in rat mammary carcinomas. Cancer Res 62: 3592-3597

Naderi A, Teschendorff AE, Barbosa-Morais NL, Pinder SE, Green AR, Powe DG, Robertson JF, Aparicio S, Ellis IO, Brenton JD, Caldas C (2007) A gene-expression signature to predict survival in breast cancer across independent data sets. Oncogene 26: 1507-1516 
O'Rourke J, Yuan R, DeWille J (1997) CCAAT/enhancer-binding protein delta (C/EBP-delta) is induced in growth-arrested mouse mammary epithelial cells. J Biol Chem 272: 6291-6296

Osada S, Yamamoto H, Nishihara T, Imagwa M (1997) DNA binding specifcity of the CCAAT/enhancer-binding protein transcription factor family. J Biol Chem 271: 3891-3896

Palmieri C, Rudraraju B, Monteverde M, Lattanzio L, Gojis O, Brizio R, Garrone O, Merlano M, Syed N, Lo Nigro C, Crook T (2012) Methylation of the calcium channel regulatory subunit $\alpha 2 \delta-3$ (CACNA2D3) predicts site-specific relapse in oestrogen receptor-positive primary breast carcinomas. Br J Cancer; e-pub ahead of print 29 May; doi:10.1038/bjc.2012.231

Pawar SA, Roy Sarkar T, Balamurugan K, Sharan S, Wang J, Zhang Y, Dowdy SF, Huang AM, Sterneck E (2010) C/EBP\{delta\} targets cyclin D1 for proteasome-mediated degradation via induction of CDC27/APC3 expression. Proc Natl Acad Sci USA 107: 9210-9215

Porter D, Lahti-Domenici J, Keshaviah A, Bae YK, Argani P, Marks J, Richardson A, Cooper A, Strausberg R, Riggins GJ, Schnitt S, Gabrielson E, Gelman R, Polyak K (2003) Molecular markers in ductal carcinoma in situ of the breast. Mol Cancer Res 1: 362-375

Porter DA, Krop IE, Nasser S, Sgroi D, Kaelin CM, Marks JR, Riggins G, Polyak K (2001) A SAGE (serial analysis of gene expression) view of breast tumor progression. Cancer Res 61: 5697-5702

Ramji DP, Foka P (2002) CCAAT/enhancer-binding proteins: structure, function and regulation. Biochem J 365: 561-575

Shah R, Smith P, Purdie C, Quinlan P, Baker L, Aman P, Thompson AM, Crook T (2009) The Prolyl 3-Hydroxylases $\mathrm{P} 3 \mathrm{H} 2$ and $\mathrm{P} 3 \mathrm{H} 3$ are novel targets for epigenetic silencing in breast cancer. Br J Cancer 100: 1687-1696

Stein T, Salomonis N, Nuyten DS, van de Vijver MJ, Gusterson BA (2009) A mouse mammary gland involution mRNA signature identifies biological pathways potentially associated with breast cancer metastasis. J Mammary Gland Biol Neoplasia 14: 99-116
Sivko GS, DeWille JW (2004) CCAAT/Enhancer binding protein delta (c/EBPdelta) regulation and expression in human mammary epithelial cells I. 'Loss of function' alterations in the c/EBPdelta growth inhibitory pathway in breast cancer cell lines. J Cell Biochem 93: 830-843

Tang D, Sivko GS, DeWille JW (2006) Promoter methylation reduces C/ EBPdelta (CEBPD) gene expression in the SUM-52PE human breast cancer cell line and in primary breast tumors. Breast Cancer Res Treat 95: 161-170

Thangaraju M, Rudelius M, Bierie B, Raffeld M, Sharan S, Hennighausen L, Huang A-M, Sterneck E (2005) C/EBPd is a crucial regulator of proapoptotic gene expression during mammary gland involution. Development 132: 4675-4685

Robinson GW, Johnson PF, Hennighausen L, Sterneck E (1998) The $\mathrm{C} / \mathrm{EBPb}$ transcription factor regulates epithelial cell proliferation and differentiation in the mammary gland. Genes Dev 12: 1907-1916

Vinson C, Myakishev M, Acharya A, Mir AA, Moll JR, Bonovich M (2002) Classification of human B-ZIP proteins based on dimerization properties. Mol Cell Biol 22: 6321-6335

Wang ND, Finegold MJ, Bradley A, Ou CN, Abdelsayed SV, Wilde MD, Taylor LR, Wilson DR, Darlington GJ (1995) Impaired energy homeostasis in C/EBPa knockout mice. Science 269: 1108-1112

Yamanaka R, Kim GD, Radomska HS, Lekstrom-Himes J, Smith LT, Antonson P, Tenen DG, Xanthopoulos KG (1997) CCAAT/enhancer binding protein $\mathrm{e}$ is preferentially up-regulated during granulocyte differentiation and its functional versatility is determined by alternative use of promoters and differential splicing. Proc Natl Acad Sci USA 94: 6462-6467

Zinszner H, Kuroda M, Wang X-Z, Batchvarova N, Lightfoot RT, Remotti $\mathrm{H}$, Stevens JL, Ron D (1998) CHOP is implicated in programmed cell death in response to impaired function of the endoplasmic reticulum. Genes Dev 12: 982-995

This work is published under the standard license to publish agreement. After 12 months the work will become freely available and the license terms will switch to a Creative Commons Attribution-NonCommercial-Share Alike 3.0 Unported License. 